\title{
1 Rapid thermal adaptation in photosymbionts of reef-building corals
}

3 Running head: Thermal adaptation in Symbiodinium

4

5 Leela J. Chakravarti ${ }^{1,2,3 *}$, Victor H. Beltran ${ }^{1}$, Madeleine J. H. van Oppen ${ }^{1,3,4}$

6

$7 \quad{ }^{1}$ Australian Institute of Marine Science, PMB No. 3, Townsville MC, Queensland 4810,

$8 \quad$ Australia

$9 \quad{ }^{2}$ College of Marine and Environmental Sciences, James Cook University, Townsville,

10 Queensland 4811, Australia

$11{ }^{3}$ Australian Research Council Centre of Excellence for Coral Reef Studies, James Cook

12 University, Townsville, Queensland 4811, Australia

$13{ }^{4}$ School of BioSciences, University of Melbourne, Parkville, Victoria 3010, Australia

14 *e-mail: leelajchakravarti@gmail.com

15

16 Key words: Symbiodinium, Acropora cytherea, Acropora hyacinthus, Acropora sarmentosa,

17 assisted evolution, experimental evolution, thermal stress, coral bleaching, Great Barrier Reef

Type of Paper: Primary research article 


\section{Abstract}

Climate warming is occurring at a rate not experienced by life on Earth for 10s of millions of years and it is unknown whether the coral-dinoflagellate (Symbiodinium spp.) symbiosis can evolve fast enough to ensure coral reef persistence. Coral thermal tolerance is partly dependent on the Symbiodinium hosted. Therefore, directed laboratory evolution in Symbiodinium has been proposed as a strategy to enhance coral holobiont thermal tolerance. Using a reciprocal transplant design, we show that the upper temperature tolerance and temperature tolerance range of Symbiodinium $\mathrm{C} 1$ increased after $\sim 80$ asexual generations (2.5 years) of laboratory thermal selection. Relative to wild-type cells, selected cells showed superior photo-physiological performance and growth rate at $31^{\circ} \mathrm{C}$ in vitro, and performed no worse at $27^{\circ} \mathrm{C}$; they also had lower levels of extracellular reactive oxygen species (exROS). In contrast, wild-type cells were unable to photosynthesise or grow at $31^{\circ} \mathrm{C}$ and produced up to 17 times more exROS. In symbiosis, the increased thermal tolerance acquired $e x$ hospite was less apparent. In recruits of two of three species tested, those harbouring selected cells showed no difference in growth between the $27^{\circ} \mathrm{C}$ and $31^{\circ} \mathrm{C}$ treatments, and a trend of positive growth at both temperatures. Recruits that were inoculated with wild-type cells, however, showed a significant difference in growth rates between the $27^{\circ} \mathrm{C}$ and $31^{\circ} \mathrm{C}$ treatments, with a negative growth trend at $31^{\circ} \mathrm{C}$. There were no significant differences in the rate and severity of bleaching in coral recruits harbouring wild-type or selected cells. Our findings highlight the need for additional Symbiodinium genotypes to be tested with this assisted evolution approach. Deciphering the genetic basis of enhanced thermal tolerance in Symbiodinium and the cause behind its limited transference to the coral holobiont in this genotype of Symbiodinium C1 are important next-steps for developing methods that aim to increase coral bleaching tolerance. 
Climate warming is occurring at an unprecedented rate as a result of increasing atmospheric

$\mathrm{CO}_{2}$ and other greenhouse gasses (Hönisch et al., 2012; Zeebe et al., 2014) and has negatively affected terrestrial and marine ecosystems (Parmesan, 2006). On coral reefs, rising seawater temperatures cause the breakdown of the critical association between the coral animal and its intracellular photosymbionts, Symbiodinium spp., leading to bleaching and often coral mortality. Extensive bleaching-related loss of coral cover has occurred over the past 3-4 decades with the worst mass bleaching event on record having occurred most recently during the 2015-16 El Niño temperature anomaly (Eakin et al., 2016; Normile, 2016; Hughes et al., 2017) where over $60 \%$ of reefs surveyed on the Great Barrier Reef (GBR) experienced extreme bleaching (Hughes et al., 2017). The frequency and severity of such heating events are anticipated to increase in the future with climate models predicting up to $99 \%$ of the world's coral reefs to experience severe annual bleaching before 2100 (van Hooidonk et al., 2016)

Increases in temperature can affect Symbiodinium and the coral host in a number of ways. The photosynthetic machinery of Symbiodinium is sensitive to even moderate temperature increases, causing photoinhibition and photodamage (Warner et al., 1999) of photosystem II (PSII, Iglesias-Prieto et al. 1992) and a disruption of the structural integrity of the chloroplast thylakoid membranes (Tchernov et al., 2004). Such changes limit the fixation of $\mathrm{CO}_{2}$ (Murata et al., 2007), thus affecting Symbiodinium cell growth. The transfer of photosynthate from the symbionts to the coral tissues accounts for up to $95 \%$ of the coral's total energy requirements (Bythell, 1988; Falkowski et al., 1993; Yellowlees et al., 2008) and a reduction in the amount of photosynthetically fixed carbon produced and translocated from symbiont to 
host can lead to reduced coral growth (Goreau \& Macfarlane, 1990; Cantin et al., 2009) and tissue loss (Szmant \& Gassman, 1990). Furthermore, under heat stress, an excess production of reactive oxygen species (ROS) in the chloroplast can cause damage to DNA, proteins and lipids and in turn ROS can cause further detriment to photosynthetic activity by inhibiting PSII repair mechanisms (Murata et al., 2007) and damaging photosynthetic membranes (Lesser, 2006). Importantly, leakage of ROS out of the cell (extracellular ROS or exROS) by Symbiodinium, when produced in excess, has been linked to coral bleaching by stimulating the expulsion or digestion of Symbiodinium by host cells, or the removal of Symbiodinium by apoptotic host cell death (Weis, 2008).

Many coral species live near their upper thermal limits and it is unlikely that physiological plasticity will enable them to mount a response great enough to cope with further environmental change (Hoegh-Guldberg et al., 2008). When physiological limits are exceeded, survival may depend on genetic adaptation through natural selection (Hoffmann \& Sgrò, 2011). However, the generally long sexual generation times of corals (2-20 years) in the face of rapid ocean warming, renders coral species unlikely to undergo significant adaptation in time to persist into the future (Hughes et al., 2003). Coral thermal tolerance is partly dependent on the genetic variant(s) of Symbiodinium that they host (Baker, 2003; Baker et al., 2004; Berkelmans \& van Oppen, 2006; Sampayo et al., 2008; Mieog et al., 2009; Howells et al., 2012). A fast rate of asexual reproduction (three to 74 days [Wilkerson et al., 1988]) in Symbiodinium, in combination with their large population sizes $\left(\sim 10^{10}\right.$ cells in a branching coral $~ 30 \mathrm{~cm}$ diameter in size [van Oppen et al., 2011]), has the potential to give rise to many spontaneous, random mutations over a short period of time, a small number of which may be beneficial to the changed conditions experienced due to climate change. These properties suggest a high adaptive potential exists in Symbiodinium. However in 
hospite, host factors may actively retard the rate of asexual division in Symbiodinium where the host can regulate growth through carbon allocation (Stat et al., 2008) and the active digestion or removal of Symbiodinium cells (Titlyanov et al., 1996). Such factors could slow Symbiodinium generation times and thus rates of evolution in hospite. This has led to the proposal of in vitro laboratory evolution in Symbiodinium with subsequent inoculation of the coral host, to be used as a potential conservation or restoration tool in assisting corals in coping with ongoing ocean warming (van Oppen et al., 2015, 2017).

Despite the potentially high adaptive capacity of Symbiodinium, most warming perturbation studies on these coral photosymbionts have been carried out over short time-scales with treatment exposure lasting few generations. Although such experiments show that thermal acclimation, equating to temperature changes on a seasonal scale, are possible in Symbiodinium (Takahashi et al., 2013), little is known about the longer-term, evolutionary consequences of ongoing ocean warming. Only one study has examined the longer-term response of Symbiodinium to ocean warming, reporting that Symbiodinium strains CCMP 2429 and CCMP 2433 (isolated from Heliofungia actiformis and Pocillopora damicornis, respectively) from the GBR were able to grow at $30^{\circ} \mathrm{C}$ after $55-70$ generations of temperature selection, where previously they could not (Huertas et al., 2011). Long-term, evolutionary experiments involving other microalgae have mainly looked at their response to elevated $\mathrm{pCO}_{2}$ and not temperature (Collins \& Bell, 2004, 2006; Flores-Moya et al., 2012; Lohbeck et al., 2012; Jin et al., 2013) ;but see Flores-Moya et al., 2012; Schlüter et al., 2014). Some of these experiments have provided evidence for the evolution of key fitness traits across multiple generations in the laboratory (Flores-Moya et al., 2012; Lohbeck et al., 2012; Jin et al., 2013), most commonly using reciprocal transplant experiments (Lohbeck et al., 2012; Jin et al., 2013; Schlüter et al., 2014) to infer adaptation. 
To examine whether rapid thermal adaptation of Symbiodinium is possible, we conducted a laboratory selection experiment using a monoclonal culture of Symbiodinium (type C1) that is common in reef-building corals and widespread on coral reefs around the world (Fabina et al., 2012; Franklin et al., 2012; Thornhill et al., 2014). In our study, Symbiodinium C1 was isolated from a colony of Acropora tenuis on the Great Barrier Reef (GBR) and 16 culture replicates, each representing an independent evolutionary unit accumulating independent mutations, underwent a ratchet experiment (Huertas et al., 2011) designed to select for increased temperature tolerance. After the ratchet experiment (lasting $\sim 5$ generations), the selected Symbiodinium cells were cultured for a further $\sim 73$ generations (approximately 2.5 years) at $31^{\circ} \mathrm{C}$, while the ancestral monoclonal culture from which it was derived (the wild type [WT]) remained at $27^{\circ} \mathrm{C}$ for the same period of time (Table 1). To determine whether the selected Symbiodinium (SS) had adapted rather than (reversibly) acclimated to $31^{\circ} \mathrm{C}$, replicate cultures of the SS and WT were subjected to a reciprocal transplant experiment (i.e., WT@27, SS@27,WT@31, and SS@31); the most direct approach for conferring adaptive change (Lohbeck et al., 2012; Jin et al., 2013; Merilä \& Hendry, 2014; Schlüter et al., 2014).

The mean fitness of the WT and SS was assessed based on a number of key traits. Six photophysiological traits were measured; the photochemical efficiency of PSII in the dark (Fv/Fm) and the light $(\Delta \mathrm{Fv} / \mathrm{Fm}$ '; indicators of the maximum and effective quantum yield of PSII, respectively), the maximum excitation pressure over PSII ( $\mathrm{Q}_{\mathrm{m}}$, Iglesias-Prieto et al., [2004]), the maximum electron transport rate (rETRm; an indicator of maximum photosynthetic capacity, Schreiber [2004]), the minimum saturating irradiance of photosynthesis $\left(\mathrm{E}_{\mathrm{k}}\right.$, Henley, [1993]) and maximum non-photochemical quenching (NPQm; a photo-protective 
mechanism involving the dissipation of excess light energy as heat, Ralph et al., [2002]).

144 Two additional traits, the specific growth rate and the amount of exROS per cell were also compared between WT and SS cells at ambient and elevated temperature.

147 To understand the impact of in vitro thermal selection of Symbiodinium on coral bleaching susceptibility, we inoculated aposymbiotic recruits of three GBR coral species, Acropora cytherea, A. hyacinthus and A. sarmentosa, with the WT and SS cells and subjected them to heat stress. For this experiment, we used the same environmental conditions that were used in the in vitro reciprocal transplant experiment. After inoculation with the WT and SS Symbiodinium, recruits were reared for five weeks at $27^{\circ} \mathrm{C}$ before being subjected to the different treatments for 28 days, during which their thermal tolerance was assessed based on growth (increase in recruit size) and the extent of bleaching (proportion of recruit surface that was pigmented).

157 Our study tests the evolutionary consequences of culturing Symbiodinium under thermal stress, adding to the important field of micro-algal adaptation through experimental evolution. Furthermore, our results provide insights into the use of experimentally evolved Symbiodinium as a potential conservation or restoration tool that aims to increase coral thermal tolerance. 
Symbiodinium cells were extracted from the coral A. tenuis, Nelly Bay, Magnetic Island, Australia $\left(19^{\circ} 10^{\prime} 6^{\prime}\right.$ ' S, $146^{\circ} 50^{\prime} 60^{\prime}$ 'E) in 2010. Extraction occurred by air-brushing the coral tissue from the coral skeleton, centrifuging ( $5 \mathrm{~min}, 1600 \mathrm{~g}$ ), decanting, and resuspending the pellet three times in $0.2 \mu \mathrm{m}$ filtered seawater. Extracted cells were transferred into sterile culture media, Daigo's IMK for Marine Microalgae (Nihon Pharmaceutical Co., Ltd) containing antibiotics (penicillin, neomycin, streptomycin, nystatin, final concentration $[100 \mu \mathrm{g} / \mathrm{mL}]$ each, amphotericin final $[2.5 \mu \mathrm{g} / \mathrm{mL}]$, plus $\mathrm{GeO}_{2}$ final [50 $\left.\mu \mathrm{M}\right]$ (Beltran et al., 2012). Cells were inoculated into fresh IMK+antibiotics monthly, for five months to minimise bacterial contamination. This heterogeneous culture was previously used by Howells et al. (2011) and Levin et al. (2016). Subsequently, cells were plated onto IMK+antibiotics and 1\% agar. A monoclonal culture was created by picking cells from a single colony forming unit. Monoclonal cultures were grown in IMK without antibiotics. The monoclonal strain was confirmed as belonging to the subclade $\mathrm{C} 1$ based on the ITS2 rDNA region (GenBank accession number AB778664.1) and named SCF055-1. Annual sequencing checks confirmed that the culture did not become contaminated during longer-term laboratory culture.

\section{Symbiodinium thermal selection and long-term culture}

The monoclonal culture was maintained at $27^{\circ} \mathrm{C}$ and $65 \pm 10 \mu \mathrm{mol}$ photons.m ${ }^{-2} \cdot \mathrm{s}^{-1}$ (Sylvania FHO24W/T5/865 fluorescent tubes) under a 14:10 light:dark cycle for $\sim 6$ months before undergoing a thermal selection experiment. Thermal selection was performed using a ratchetdesign (Huertas et al. 2011) lasting two months ( $\sim 5$ generations). The ratchet design is a method that maintains large population sizes by increasing the temperature in a step-wise fashion. With this approach, a population is only subjected to increased temperature (i.e., the 
next ratchet) when it shows positive growth. By maintaining population growth, this method maximises the number of spontaneous mutations arising from asexual cell division. With increasing levels of thermal selection pressure; natural selection can then act upon beneficial new mutations. This design allows the selection of best performers (assumed to be mutants as genetically homogenous monoclonal cultures are used) at each temperature ratchet.

Replicates $(n=16)$ of the monoclonal culture were inoculated into fresh media at 300000 cells $\mathrm{mL}^{-1}$ and placed at $26^{\circ} \mathrm{C}$. High replication was used initially to increase the chances of a spontaneous, beneficial new mutation occurring in at least one population. Importantly, each 'replicate' population was no longer considered a replicate once the experiment commenced, but an independent population representing a different random chance for a beneficial mutation to arise (Huertas et al., 2011). After 30 days, the four populations displaying the highest growth at $28^{\circ} \mathrm{C}$, or the greatest cell densities, were transferred to the next ratchet temperature $\left(2^{\circ} \mathrm{C}\right.$ higher than the previous) and split between four more vessels containing fresh media, at the same starting cell density, resulting in $\mathrm{n}=16$ populations at both $28^{\circ} \mathrm{C}$ and $30^{\circ} \mathrm{C}$, respectively. Those kept at the next ratchet temperature of $32^{\circ} \mathrm{C}$, however, did not exhibit any net growth and $30^{\circ} \mathrm{C}$ was considered their maximum adaptive capacity. The cells able to survive and grow at an elevated temperature are hereafter named the selected Symbiodinium (SS) and their counterpart cells, that remained in control temperatures, named the wild-type (WT). Following the ratchet experiment, ten randomly selected WT populations were kept at $26.63 \pm 0.001^{\circ} \mathrm{C}$ and ten of the fastest growing SS populations, resulting from the selection experiment, were kept at $31.16 \pm 0.002^{\circ} \mathrm{C}$ and cultured separately for approximately 30 months ( $c a .142$ and 73 generations, respectively, see below for description on estimation of generation number). The ten WT populations were named SCF055-1-1 to SCF055-1-10 and ten SS populations were named SCF055-1-11 to SCF055- 
1-20. Temperature measurements were recorded every $10 \mathrm{~min}$, using a data logger (HOBO Pendant ${ }^{\circledR}$ Table 1). Monthly, each WT and SS population was sub-cultured into fresh culture media (IMK).

\section{Experiment 1: In vitro reciprocal transplant}

\section{Experimental design}

We chose the SS population that had the greatest cell density at $31^{\circ} \mathrm{C}$ (SCF055-1-18), two weeks after sub-culturing, and a randomly chosen WT population (SCF055-1-3). To test whether adaptation in the SS cells had arisen from long-term acclimation or from genetic selection on beneficial mutations arisen through cell division the SS and WT cells then underwent a reciprocal transplant experiment. SS and WT cells were pre-acclimated for two weeks in their own (WT@27 and SS@31) or transplanted into reciprocal (WT@31 and SS@27) temperature conditions at a starting cell density of 200000 cells $\mathrm{mL}^{-1}$. The preacclimated cells were then transferred to culture vessels $\left(25 \mathrm{~cm}^{2}\right.$, Corning ${ }^{\circledR}$, Sigma-Aldrich $)$ containing $10 \mathrm{~mL}$ of fresh media at a density of 200000 cells $\mathrm{mL}^{-1}$ to give 12 replicate cultures for each of the four treatments. This replicate number was chosen so that at least three replicates could be used for the quantification of different physiological traits (see below).

During a previous study, using the heterogeneous population from which our WT strain was derived, heating for 15 days at $32^{\circ} \mathrm{C}$ revealed no difference in performance traits under elevated compared to ambient temperature conditions (Levin et al., 2016). Therefore, we did not carry out performance measurements until day 3, post-acclimation (representing 17 days in temperature treatment conditions). On days 3, 7, 10, 14, 17 and 21 (D3-D21) post- 
acclimation, measurements for photosynthetic performance and growth were taken in six replicates (replicates seven to 12). On D7, D14 and D21 post-inoculation, three replicates from each transplant (D7 -replicates one to three, D14 - four to six and D21 - seven to nine) were sacrificed for the measurement of extracellular ROS (exROS) production. Cells therefore spent a total of five weeks in experimental conditions, corresponding to up to eight asexual generations. For bacteria, seven generations are enough to attribute whether adaptation has occurred through genetic mechanisms or through acclimation (Cooper, 1991), where genetic adaptation is shown by the difference in growth rate of selected cells under the selective conditions (SS@31) with the growth rate of the wild-type cells that have been transferred to the selective conditions (WT@31).

\section{Photosynthetic performance}

The maximum quantum yield of PSII fluorescence $\left(F_{v} / F_{m}=F_{m}-\left(F_{0} / F_{m}\right)\right)$ was measured one hour before the end of the dark cycle, while the effective quantum yield $\left(\Delta F / \mathrm{F}_{\mathrm{m}}\right.$ ') of PSII was measured after six hours of light exposure. Both maximum and effective quantum yield measurements were carried out using an imaging pulse amplitude fluorometer (iPAM, Walz), with a Measuring Intensity of four, Saturating Intensity of seven, and Gain and Damping of two. PAM settings were chosen based on preliminary experiments as a compromise between fluorescence detection of low cell densities and signal saturation for high cell densities. The maximum excitation pressure over PSII $\left(\mathrm{Q}_{\mathrm{m}}\right)$ was calculated using measurements for the maximum and effective quantum yields of PSII (Iglesias-Prieto et al., 2004) using the equation

$$
Q_{m}=1-\left[\left(\Delta F / F_{m}{ }^{\prime}\right) /\left(F_{v} / F_{m}\right)\right]
$$

Rapid light curves (RLCs) were carried out following $\Delta F / \mathrm{F}_{\mathrm{m}}$ ' measurements by exposing each replicate culture to 10 steps of increasing actinic light (0-461 $\mu \mathrm{mol}$ photons $\left.\mathrm{m}^{-2} \mathrm{~s}^{-1} \mathrm{PAR}\right)$ 
each lasting $10 \mathrm{~s}$. The RLCs for each replicate were fitted to the model by Platt et al. (Platt $e t$ al., 1980). The parameters of $\mathrm{rETR}_{\mathrm{m}}$ and $\mathrm{E}_{\mathrm{k}}$ were calculated using SigmaPlot (Hill et al., 2004). By D17 and D21, the WT@31 replicates were no longer able to respond to the increases in light induced by the RLCs and data could not be fitted to the model. Values for $E_{k}$ could therefore not be calculated at these time points. Non-photochemical quenching (NPQ) was calculated for each step of the RLCs using the equation

Values for the maximum NPQ $\left(\mathrm{NPQ}_{\mathrm{m}}\right)$ were extracted from the highest PAR exposure during the RLCs.

Growth rate and estimation of cell generation number

For cell density measurements, aliquots of $50 \mu \mathrm{L}$ from replicates six to $12(n=6)$ were fixed by adding $4 \mu \mathrm{L}$ of $25 \%$ glutaraldehyde and stored at $4{ }^{\circ} \mathrm{C}$ for later measurements of cell density. Cell density was determined by triplicate haemocytometer counts and specific growth rate $\left(\mu\right.$, doubling day $\left.{ }^{-1}\right)$ was calculated as

where $N_{0}$ is the cell density at D3, $N_{l}$ is the cell density at D17 and $t$ is the duration (17-3) of culture in days. Cell density values for D3 and D17 were chosen as they represented the fastest growth rates during the experiment.

To estimate the number of generations that both the WT@27 had SS@31 had been through, both during their long-term culture and the reciprocal transplant experiment, we used cell density values from the three week experimental phase of the reciprocal transplant 
experiment. First, the doubling time (or generation time) was calculated according to the equation

$$
T=21 \times\left(\frac{\log (2)}{\log \left(\frac{N_{1}}{N_{0}}\right)}\right)
$$

where $N_{l}$ is the end cell density after 21 days of growth and $N_{0}$ is the cell density at the start of the experiment $\left(200000\right.$ cells $\left.\mathrm{mL}^{-1}\right)$. Next the number of generations was calculated as

$$
\text { Generations }=N / T
$$

Where $N$ is the number of days of long-term culture (e.g., 840 days post-ratchet experiment) and $T$ is the doubling time. Although doubling times could have varied during the long-term culture, to provide an estimate of the generation number, we assume that they were constant.

\section{Extracellular ROS production}

For extracellular reactive oxygen species (exROS) determination, $1 \mathrm{~mL}$ of culture from each sacrificial replicate $(n=3)$ was pelleted $(295 \mathrm{~g} / 2000 \mathrm{rpm}, 5 \mathrm{~min})$ and $250 \mu \mathrm{L}$ of the supernatant from each replicate was plated three times into a black, clear-bottom 96-well culture plate (Costar, Corning ${ }^{\circledR}$, Sigma-Aldrich). The supernatant was incubated with $0.5 \mu \mathrm{L}$ of CellROX Orange (Levin et al., 2016) (final concentration $5 \mu \mathrm{m}, 25 \mathrm{~min}$ at $37^{\circ} \mathrm{C}$ ), a fluorogenic probe that exhibits orange fluorescence upon oxidation by ROS (545 nm absorption, $565 \mathrm{~nm}$ emission). Fluorescence measurements were taken using a microplate reader (Synergy ${ }^{\mathrm{TM}} \mathrm{H} 4$ Hybrid, Biotek $\left.®\right)$ immediately after incubation. Prior to pelleting, an aliquot of $50 \mu \mathrm{L}$ from each sacrificial replicate was taken for the determination of cell density. The three fluorescence values for each replicate were then standardised to cell number to give relative exROS production per cell in arbitrary fluorescent units. 


\section{Experiment 2: in hospite reciprocal transplant experiment}

306

307

\section{Coral settlement and inoculation with Symbiodinium}

To determine whether thermal selection in Symbiodinium could enhance the thermal tolerance of the holobiont we chose three species of coral, Acropora cytherea, A. hyacinthus and A. sarmentosa. Coral colonies of each species were collected from Trunk Reef, Great Barrier Reef, Australia (18 $18^{\circ} 101^{\prime}, \mathrm{S}, 146^{\circ} 52^{\prime} 226^{\prime}$ ' E) and kept in the National Sea Simulator (SeaSim) at the Australian Institute of Marine Science (Townsville, Australia) for three days before the full moon. Following spawning, gametes from four colonies of $A$. cytherea and five of A. hyacinthus and A. sarmentosa were each mixed in equal quantities (sperm concentration: $\sim 10^{6} \mathrm{~mL}^{-1}$ ), within a species, for fertilisation. Resulting larvae were kept in aerated $0.4 \mu \mathrm{m}$ filtered seawater for $c a$. three weeks.

Six-well, multi-well plates (well volume $16.8 \mathrm{~mL}$, Corning $^{\circledR}$, Sigma-Aldrich $^{\circledR}$ ) were prepared with a settlement cue- the peptide Hym-248 (Iwao et al., 2002), by placing three, $3 \mu \mathrm{L}$ droplets of $60 \mu \mathrm{M}$ in each well, and leaving to dry. These droplets were placed at equal distance from the edge of each well using a template placed underneath the plate. Planulae were taken from the SeaSim and washed three times in 0.2 micron filtered seawater (FSW). Three, $90 \mu \mathrm{L}$ droplets of FSW, each containing one planula, were plated into each well on top of the dried peptide dots. Planulae were left for $12 \mathrm{~h}$ in their droplets, in the dark, at $27^{\circ} \mathrm{C}$ to metamorphose and settle. Subsequently, each well was filled with $9 \mathrm{~mL}$ of FSW and planulae that had not metamorphosed or settled were removed. This method resulted in 134 individual recruits of $A$. cytherea across 14 plates, 136 of $A$. hyacinthus across 14 plates and 125 of $A$. sarmentosa across 15 plates. Coral recruits were reared at $27{ }^{\circ} \mathrm{C}, 65 \pm 10 \mu \mathrm{mol}$ photons. $\mathrm{m}^{-2} . \mathrm{s}^{-}$

${ }^{1}$ under a 14:10 light:dark cycle and were supplemented twice weekly with a 0.2 micron, 
329 filter-sterilised cocktail of nutrients, glycerol, vitamins and amino acid as in Wang et al.

330 (2012). Plates were placed on a slow-moving, rotating shaker plate to allow the

331 homogenisation of food. Water changes were carried out the day after feeding by removing

332 the water in each well and replacing to total of $9 \mathrm{~mL}$ per well with fresh FSW.

Experimental design

Nine days post-settlement, half of the plates containing recruits were inoculated with WT cells and half with SS cells (pre-acclimated to $27^{\circ} \mathrm{C}$ for two weeks to 30000 cells $\mathrm{mL}^{-1}$ ) and left for two days before replacing each well with fresh FSW. Inoculation was repeated 12 days post-settlement to maximise the number of symbionts taken up by the recruits. Five days after the initial inoculation, recruits had visually taken up symbionts and they were subsequently reared for 5 weeks at $27^{\circ} \mathrm{C}$ to ensure the symbiosis was stable and recruits were sufficiently pigmented for further analyses. Subsequently, half of the plates containing corals infected with the WT and half of those containing corals infected with the SS were transplanted into $31^{\circ} \mathrm{C}$ (D0) while the remaining recruits were kept at $27^{\circ} \mathrm{C}$. This resulted in four experimental treatments, which mirrored those of the in vitro experiment (i.e., WT@27, SS@27, SS@31, and WT@31). For each coral species, this resulted in three to five replicate plates and between 27 and 38 individual recruits per treatment. Replicate number was considered sufficient to take into account potential variation in recruit physiology as a result of genetic variation.

\section{Recruit size and extent of pigmentation}

Images of each recruit were taken using a camera-stereomicroscope setup (SMZ800N,

Nikon) on the day of transplantation (D0), two weeks (D14) and 4 weeks (D28) posttransplantation. Images were taken while the polyp's tentacles were retracted. The same 
area of each recruit using imaging software (NIS-Elements BR v430, Nikon). This was done by detecting the outline of each recruit base and auto-calculating the area within (region of interest (ROI), Fig. 1a). Growth was expressed as the percentage change in size of each recruit at D28 from the starting size at D0.

As a proxy for bleaching, we tracked any changes in percentage pigmentation of the surface area of each recruit during the experiment. To do this, we used the images from D0, D4 and

\section{(a)}

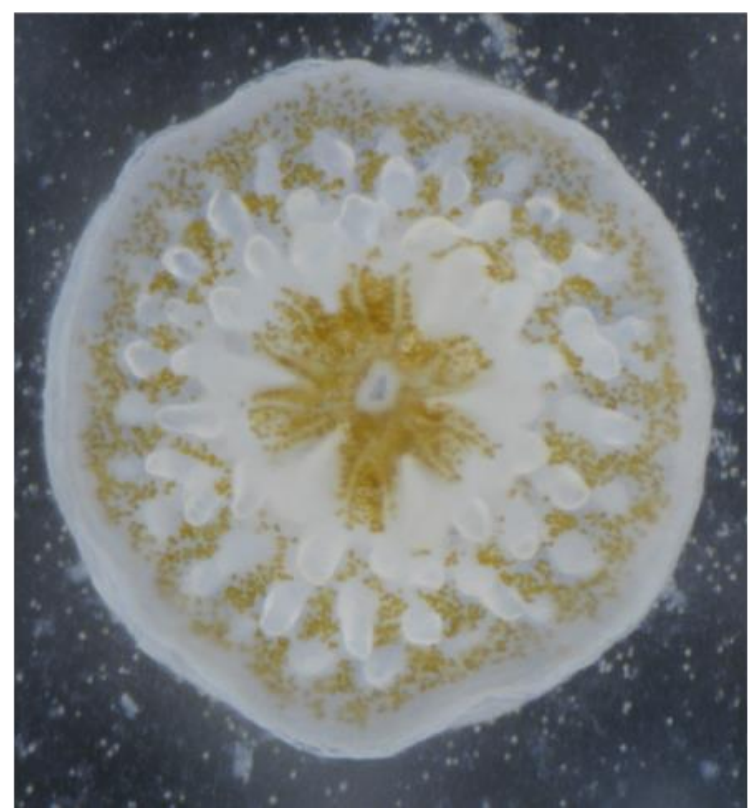

(b)

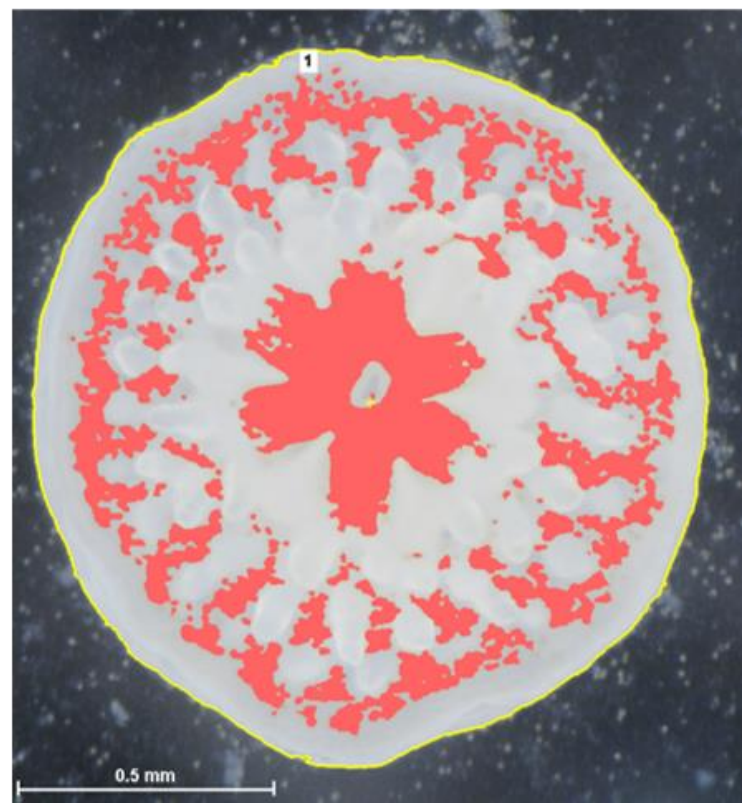

Fig. 1 Determination of recruit base area and area pigmentation (\%) of a coral recruit. (a) raw 
368 (recruit base area) and the area pigmented highlighted after applying red, green blue (RGB)

369 thresholds. The area pigmented is expressed as a percentage of the total base area of the

370 recruit.

371 Experimental water parameters

372 Throughout both the in vitro and in hospite experiments, temperature conditions were

373 measured every 10 min with a HOBO data logger (Tables 1 and 2). Light measurements were

374 checked daily during the middle of the light cycle and were always $65 \pm 10 \mu$ mol photons.m ${ }^{-}$

$375{ }^{2} \cdot \mathrm{s}^{-1}$. For the in hospite experiment, $\mathrm{pH}_{\mathrm{NBS}}$, salinity and oxygen saturation measurements were

376 taken from one random well per plate, twice weekly, coinciding with water changes (Table 2)

377 to make sure a high water quality was maintained. 
378 Table 1. In vitro culture temperature conditions for the wild-type (WT) and selected

379 Symbiodinium (SS) cells. Pre-experimental temperature refers to the long-term culture history

380 (210 weeks) of the WT and SS cells in control and elevated temperatures, respectively.

381 Experimental phase temperatures are those experienced during the reciprocal transplant

382 experiment (five weeks) by both the WT and SS cells during two weeks of pre-acclimation

383 and three weeks of experiment. Values are mean \pm SEM. Number of replicate measurements

384 are provided in parentheses.

385

\begin{tabular}{lll}
\hline Culture & Treatment & Temperature $\left({ }^{\circ} \mathrm{C}\right)$ \\
\hline Long-term & WT@ 27 & $26.63 \pm 0.001(76599)$ \\
& SS@ 31 & $31.15 \pm 0.002(77730)$ \\
Experimental & WT@ 27 & $26.85 \pm 0.005(5032)$ \\
& SS@ 27 & \\
& SS@ 31 & \\
& WT@ 31 & \\
&
\end{tabular}


387

388

389

390

391

392

393

\begin{tabular}{|c|c|c|c|c|c|}
\hline Phase & Treatment & $\begin{array}{l}\text { Temperature } \\
\left({ }^{\circ} \mathrm{C}\right)\end{array}$ & Salinity $(\% 00)$ & $\begin{array}{l}\text { Dissolved } \\
\text { Oxygen }(\%)\end{array}$ & $\mathrm{pH}_{\mathrm{NBS}}$ \\
\hline \multirow[t]{2}{*}{$\begin{array}{l}\text { Pre- } \\
\text { experimental }\end{array}$} & WT@27 & $\begin{array}{l}26.81 \pm 0.005 \\
(5183)\end{array}$ & $\begin{array}{l}33.13 \pm 0.35 \\
(127)\end{array}$ & $\begin{array}{l}97.89 \pm 0.12 \\
(127)\end{array}$ & $\begin{array}{l}8.06 \pm 0.005 \\
(127)\end{array}$ \\
\hline & SS@27 & & $\begin{array}{l}33.6 \pm 0.06 \\
(138)\end{array}$ & $\begin{array}{l}97.87 \pm 0.10 \\
(138)\end{array}$ & $\begin{array}{l}8.06 \pm 0.005 \\
(138)\end{array}$ \\
\hline \multirow[t]{4}{*}{ Experimental } & WT@27 & $\begin{array}{l}26.81 \pm 0.007 \\
(2971)\end{array}$ & $\begin{array}{l}33.36 \pm 0.07 \\
(66)\end{array}$ & $\begin{array}{l}96.83 \pm 0.18 \\
(66)\end{array}$ & $\begin{array}{l}8.09 \pm 0.008 \\
(66)\end{array}$ \\
\hline & SS@27 & & $\begin{array}{l}33.49 \pm 0.09 \\
(66)\end{array}$ & $\begin{array}{l}96.12 \pm 0.53 \\
(66)\end{array}$ & $\begin{array}{l}8.10 \pm 0.008 \\
(66)\end{array}$ \\
\hline & SS@31 & $\begin{array}{l}31.09 \pm 0.002 \\
(3075)\end{array}$ & $\begin{array}{l}33.53 \pm 0.09 \\
(66)\end{array}$ & $\begin{array}{l}95.59 \pm 1.15 \\
(66)\end{array}$ & $\begin{array}{l}8.10 \pm 0.007 \\
(66)\end{array}$ \\
\hline & WT@31 & & $\begin{array}{l}33.53 \pm 0.09 \\
(78)\end{array}$ & $\begin{array}{l}95.92 \pm 0.02 \\
(78)\end{array}$ & $\begin{array}{l}8.10 \pm 0.007 \\
(78)\end{array}$ \\
\hline
\end{tabular}

Table 2. In hospite rearing conditions for coral recruits infected with either the wild-type (WT) or selected Symbiodinium (SS) cells in two temperature conditions. Pre-experimental conditions refer to the ambient temperature rearing conditions of recruits infected with both the WT and SS cells (five weeks) before half being moved into elevated temperature treatment during the experimental phase (three weeks). Values are mean \pm SEM. Number of replicates are provided in parentheses.$$
\text { replicates are provided in parentheses. }
$$

3

394

395

396

397

398

\section{Statistical analyses}

In vitro: To analyse the effects of temperature on the WT and SS cells, we compared the physiological responses of WT and SS cells in their own (WT@27, ST@31) and reciprocal (ST@27 and WT@31) temperature treatments across time, where relevant. To test the effects of treatment on in vitro specific growth rate and photo-physiological traits, we used a linear model with 'treatment' (i.e.WT@27, ST@31, ST@27 and WT@31) as a fixed factor and 
with 'time' as an additional fixed factor for all photo-physiological traits. The effect of treatment and time on exROS production was tested using a generalized linear mixed effects model fitted for a poisson distribution, again with 'treatment' and 'time' as fixed factors. In hospite: Similarly, to analyse the effects of temperature on the coral recruits infected with the WT and SS cells, we compared the physiological responses of corals infected with WT and SS cells in their own (WT@27, SS@31) and reciprocal (SS@27,WT@31)treatments across time, where relevant. Linear mixed effects models were used to test the effects of treatment and time on the $\%$ change in growth for each coral species, while generalized linear mixed effects models fitted for a negative binomial distribution were used to test the effects of treatment and time on area pigmentation (\%) of recruits for each coral species. In both cases, 'treatment' and 'time' were fixed factors and 'plate' was included as a random fixed factor.

All analyses were performed in R (v. 3.3.2, R Core Team, (2016)), with annotated scripts and raw data included in the Supporting Information (S1 and S2, respectively). Linear models and linear mixed effects models were carried out using the package 'nlme'(Pinheiro et al., 2017), while generalized linear mixed effects models were carried out using the package 'Ime4' (Bates et al., 2015). For both in vitro and in hospite traits, all pairwise comparisons were carried out post-hoc with Tukey's tests using the package 'multcomp'(Hothorn et al., 2008). Heterogeneity and normality were assessed using Residual and Q-Q- plots. Where 'time' was a fixed factor, we checked for correlation within the model and in all cases, none was detected.

\section{Results}

\section{Heat stress responses of Symbiodinium in vitro}


426 Photosynthetic performance: Maximum and effective quantum yield values (Figs. 2a, b) for 427 the SS@31 were not significantly different to those for the WT@27 and SS@27 throughout 428 most of the experiment, but were higher than mean values for the WT@31 (max. $p<0.05$ ). 429 The WT@31 values were always significantly lower (max. $p<0.05$ ) compared to those in 430 the remaining treatments, with the mean Fv/Fm significantly decreasing over time from 0.46 $431( \pm$ SEM, \pm 0.007$)$ to $0.37( \pm 0.004)$ and mean $\Delta \mathrm{F} / \mathrm{Fm}$ ' from $0.41( \pm 0.002)$ to $0.22( \pm 0.036)$ 432 from day 3 (D3) to day 21 (D21, $p<0.05)$. The mean maximum excitation pressure over PSII $433\left(\mathrm{Q}_{\mathrm{m}}\right.$, Fig. 2c) for the WT@31 was significantly elevated over five of the six time points, 434 compared to the other treatments (max. $p<0.05$ ), and by D21 the mean $\mathrm{Q}_{\mathrm{m}}$ had significantly 435 increased to $0.42( \pm 0.054)$ from $0.11( \pm 0.017)$ at D0 $(p<0.05)$. The mean irradiance at onset 436 of light saturation $\left(\mathrm{E}_{\mathrm{k}}\right)$, maximum relative electron transport rate $(\mathrm{rETR} \mathrm{m})$ and maximum 437 NPQ $\left(\mathrm{NPQ}_{\mathrm{m}}\right)$ for the WT@31 were significantly lower than for the remaining experimental 438 groups (max. $p<0.05)$ across the duration of the experiment (Fig $2 \mathrm{~d}-\mathrm{f}$ ) with the mean $\mathrm{rTTR}_{\mathrm{m}}$ 439 significantly decreasing over time $(p<0.05)$. One exception was at D7, when the mean $\mathrm{E}_{\mathrm{k}}$ 440 value was not statistically different from that in the SS@27 and WT@27 treatments (min. $p>$ $4410.05)$. 
(a)

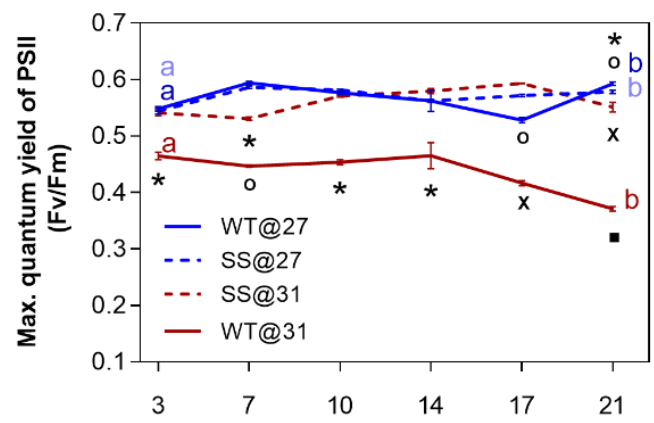

(b)

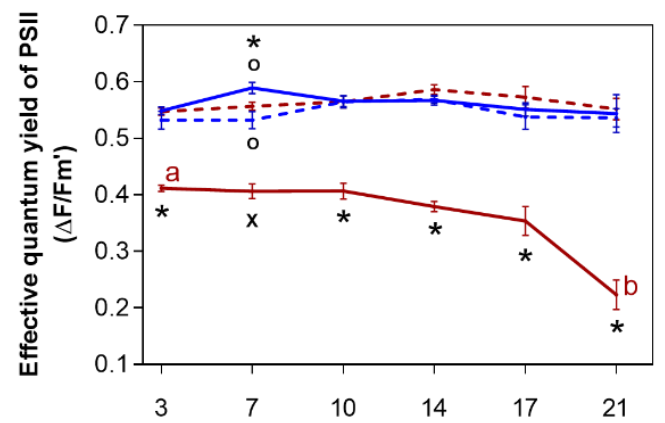

(c)

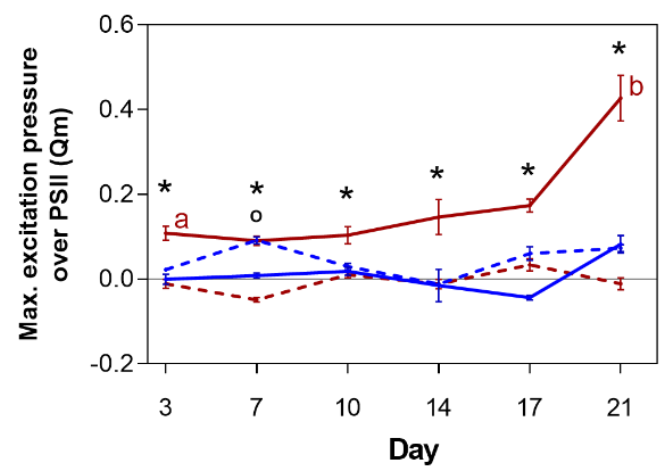

(d)

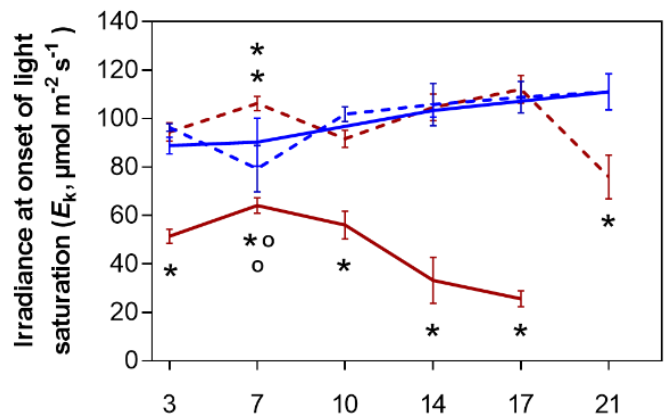

(e)

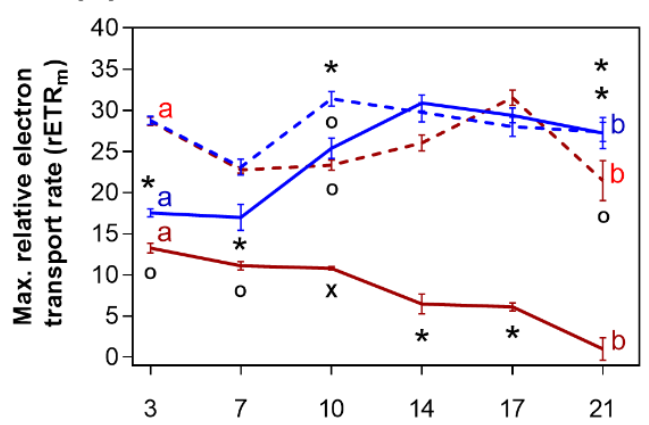

(f)

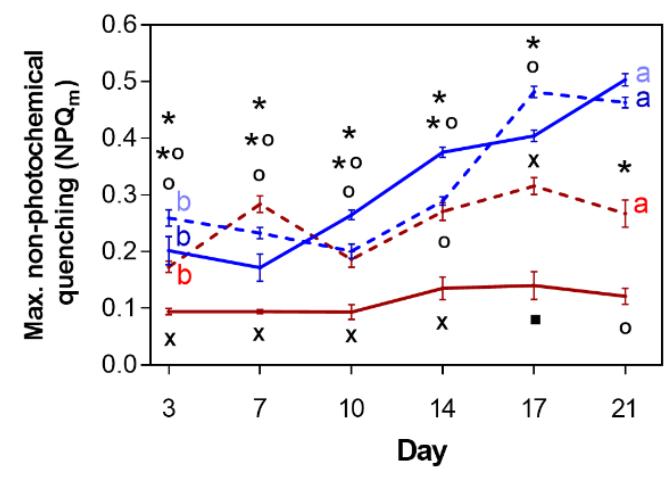

Fig. 2 Comparison of mean $( \pm S E M)$ photochemical performance traits in wild-type (WT) and selected (SS) Symbiodinium C1 at 27C (WT@27, SS@27) and 31 ${ }^{\circ} \mathrm{C}$ (SS@31, WT@ 31) over 21 days after 14 days of pre-acclimation. (a), Maximum quantum yield of photosystem

447 photosystem II. (d), Irradiance at onset of light saturation. (e) Maximum relative electron transport rate. (f) Maximum non-photochemical quenching. Statistically significant differences among ‘treatments'(i.e.WT@27, SS@27, SS@31,WT@31)within a time point are represented by different symbols above/below the line plots, while statistically significant 
differences over time (between D3 and D21) for each treatment are represented by different letters (Tukey's post hoc tests; $p<0.05$ ). $\mathrm{n}=6$ for all means. Where error bars are not visible, they are small and hidden by the symbols.

Specific growth rate: The mean growth rate of SS@31 was positive at $0.07 \mu \pm 0.005$. Although this was significantly slower than the growth rates of the WT@27 $(0.16 \pm 0.007)$ and SS@27 (0.14 $\pm 0.008, \max . p<0.05)$, all three had significantly greater mean growth rates compared to the WT@31 (max. $p<0.05$ ), which exhibited negative growth at $0.05 \mu$ ( \pm 0.010 , Fig. 3a).

Oxidative stress: ExROS of the WT@31 had mean values that were always significantly greater than those observed for the other experimental groups (max. $p<0.05$ ) and that significantly increased over time from $46.2( \pm 2.04)$ at D7 to $105.62( \pm 22.25)$ by D21 $(p<$ 0.05, Fig. 3b). By comparison, the highest mean value of SS@ 31 throughout the experiment was $22.19( \pm 4.10)$. The amount of ExROS produced in the SS@31 treatment was not significantly different to that of the SS@27 or WT@27 at any time point $(p>0.05)$ and the production of exROS by SS@31, SS@37 or SS@27 did not significantly change over time ( $p$ $>0.05)$. 
(a)

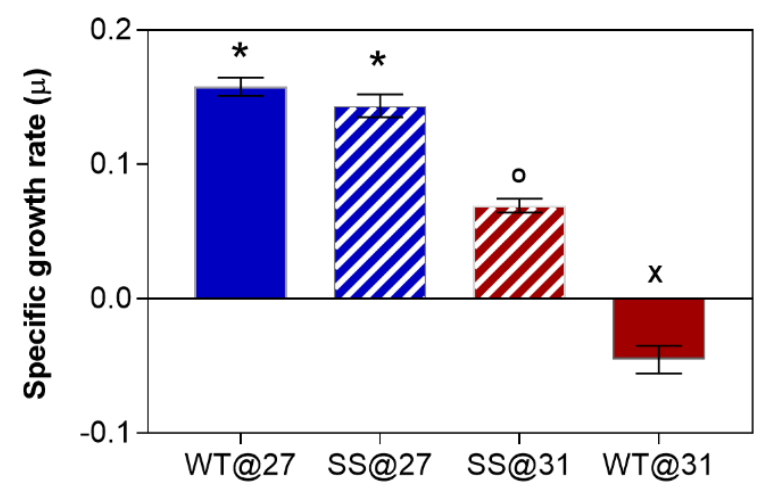

(b)

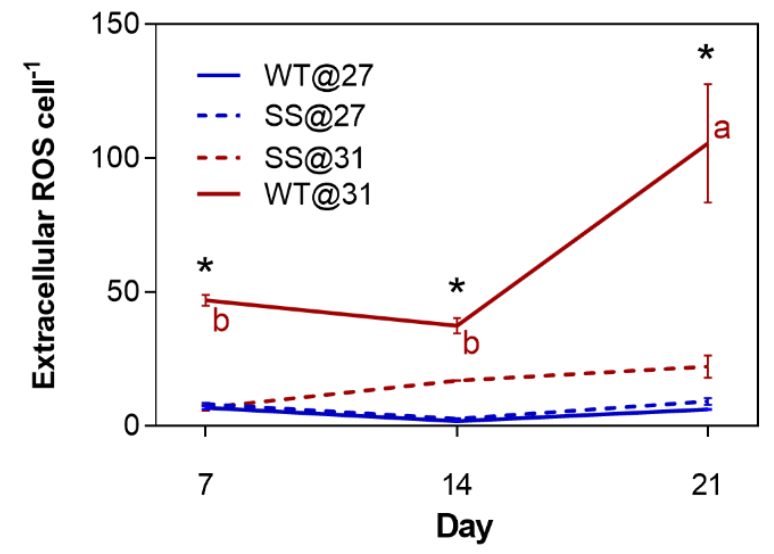

471 Fig. 3 Comparison of mean $( \pm$ SEM) growth and oxidative stress of wild-type (WT) and

472

473

474

475

476

477

478

479

480

481

482

483

484

485

486

487 selected (SS) Symbiodinium C1 at 27C (WT@27, SS@27) and 31ํㄷ (SS@31, WT@ 31) after 14 days of pre-acclimation. (a), Specific growth rate $(n=6)$ calculated from cell densities at D3 and D17. (b), Extracellular reactive oxygen species production per cell $(\mathrm{n}=$ 3). Statistically significant differences among ‘treatments’ (i.e.WT@27, SS@27, SS@31, WT@ 31) are represented by different symbols above/below the bar/line plots (Tukey’s post hoc tests; $p<0.05)(\mathbf{a}, \mathbf{b})$. Statistically significant differences over time for each treatment are represented by different letters (b). Where error bars are not visible, they are small and hidden by the symbols.

\section{Heat stress responses of the juvenile coral holobiont}

Growth: Measurements of percentage change in size over the 28-day experiment (Figs. 4a-c) revealed no significant differences in growth between the WT@27, SS@27 and SS@31 recruits for each coral species (min. $p=>0.05$ ), which generally showed a trend of positive mean growth with increases up to $1.29 \pm 0.52 \%$ over the four-week experiment. In contrast, WT@31 recruits displayed a trend of negative mean growth for all three coral species.

Despite this, the mean growth of the WT@31 recruits was not significantly different from 
that of the SS@31 recruits for all three coral species (min. $p>0.05$ ), although it was significantly lower compared to that of the WT@27 recruits for A. cytherea and A. hyacinthus (max. $p<0.05$ ). The WT@31 mean growth was significantly lower compared to that of the SS@27 recruits for A. hyacinthus and A. cytherea $(p<0.05)$.

\section{Area pigmented:}

There were no significant differences in mean percentage pigmentation at D0 for all coral species harbouring either the ST or WT cells ( $p>0.05$, Figs. 4d-f). By D14 the mean percentage pigmentation of all three coral species harbouring the SS and WT cells had not significantly changed in the $31^{\circ} \mathrm{C}$ treatment $(p>0.05)$, while the majority of those harbouring the WT and SS at $27^{\circ} \mathrm{C}$ had increased $(p<0.05)$. While the recruits harbouring WT cells were significantly less pigmented at $31^{\circ} \mathrm{C}$ than those at $27^{\circ} \mathrm{C}$ across the duration of the experiment $(\max . p>0.05)$ ), the mean percentage pigmentation for recruits in the SS@ 31 treatment across all three species was not significantly different to the recruits harbouring the WT or ST cells at $27^{\circ} \mathrm{C}$ (min. $p>0.05$ ). The only exception was A. hyacinthus, where the mean percentage pigmentation for SS-recruits at $31^{\circ} \mathrm{C}$ was significantly lower than the for WT-recruits at $27^{\circ} \mathrm{C}(p<0.05$, Fig. 4e). By D28, WT and SS recruits of all three species had bleached at $31^{\circ} \mathrm{C}(0.75-6.51 \%$ mean pigmentation $)$, with mean pigmentation values not significantly different between the WT and SS recruits (min. $p>0.05$ ) as well as being significantly less pigmented compared to the recruits at D0 (min. $p>0.05$ ). 
(a)

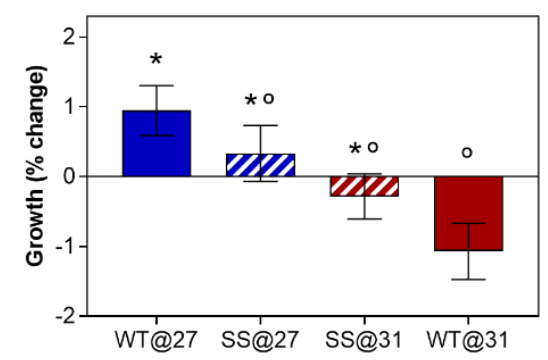

(d)

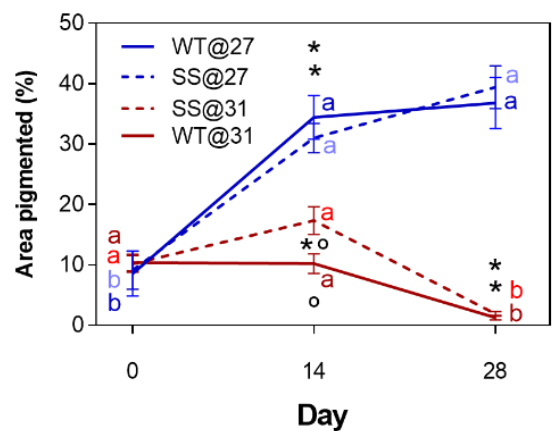

Day (b)

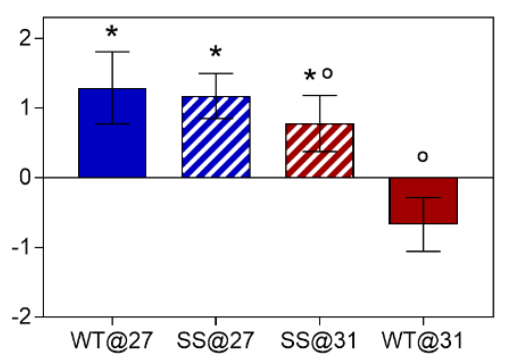

(e)

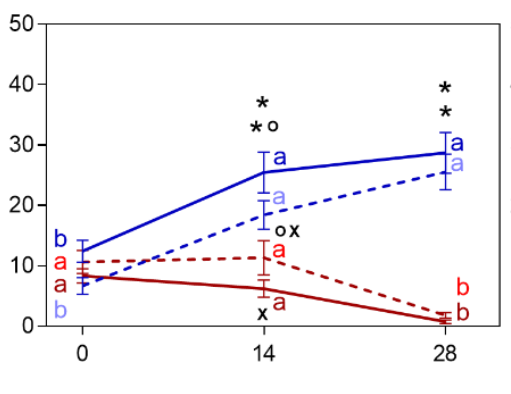

Day (c)

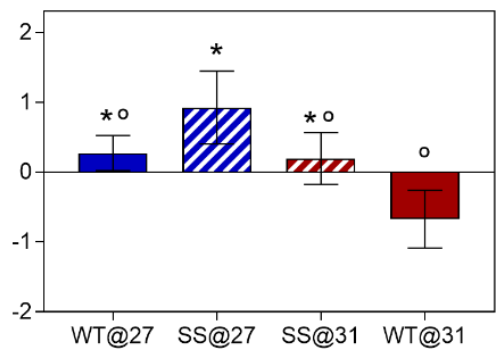

(f)

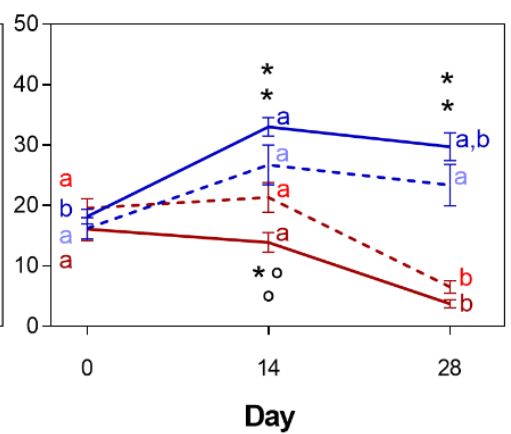

508

Fig. 4 Comparison of mean $( \pm$ SEM) growth, bleaching and photochemical performance of coral recruits harbouring wild-type (WT) and selected (SS) Symbiodinium C1 at $27^{\circ} \mathrm{C}$

511 (WT@27, SS@27) and 31 ${ }^{\circ} \mathrm{C}$ (SS@31,WT@31). (a - c) \% change in size between D0 and D28 for three coral species $(n=25-34)$. $(\mathbf{d}-\mathbf{f})$ Proportion of recruit surface area pigmented $(\%)$ for each coral species $(\mathrm{n}=20-37)$. Statistically significant differences among ‘treatments’ (i.e.WT@27,SS@27,SS@31,WT@31)within a time point are represented by different symbols above/below the line plots (Tukey's post hoc tests; $p<0.05$, a-f).

516 Statistically significant differences over time (d-f) for each treatment are represented by

517 different letters (Tukey’s post hoc tests; $p<0.05$ ). Where error bars are not visible, they are small and hidden by the symbols. 
The stable phenotypic changes observed in the SS cells after $\sim 80$ generations (2.5 years) of in

522 vitro selection provides compelling evidence of rapid thermal adaptation in this Symbiodinium type $\mathrm{C} 1$ genotype. Our study is one of only a few micro-algal studies that show thermal adaptation through experimental evolution. SS cells significantly outperformed the WT cells at elevated temperature for all traits measured while they maintained performance levels similar to those of the WT cells at ambient temperature, demonstrating that laboratory selection has widened rather than shifted the SS temperature tolerance range for this strain. This is an important characteristic considering the often large natural daily and seasonal temperature fluctuations experienced on coral reefs (Kline et al., 2015). Contrary to expectations, we found the positive effects of thermal adaptation of the SS cells to be considerably reduced in hospite, although a trend of positive growth was observed in two of three coral species tested under heat stress when inoculated with SS cells, but not with WT cells.

\section{Thermal adaptation and broadening of thermal range in algal endosymbionts ex hospite}

All photo-physiological traits measured showed a significantly lowered performance of the WT@ 31 compared to the other experimental groups over the 21 day study period. In contrast, the SS@31, could maintain photosynthetic function similar to the WT@27 and SS@27 throughout the experiment. The specific growth rate and exROS data confirm an increase in temperature tolerance for the SS relative to the WT cells. The mean growth rate of SS@ 31 , while up to 44\% slower than that of the WT@27 and SS@ 27, exhibited positive growth $(0.07$ doublings day ${ }^{-1}$ ), while the WT@31 exhibited mean negative growth of -0.05 doublings day ${ }^{-}$

${ }^{1}$. Elevated temperature inevitably requires increases in metabolic activity (Beardall \& Raven, 2004). Selection on more efficient metabolic pathways for the SS may have been enough to 
maintain energetically costly photosynthetic processes (and/or photosystem and cellular repair mechanisms) as well as positive growth at $31^{\circ} \mathrm{C}$, but not enough to sustain growth rates to match those at $27^{\circ} \mathrm{C}$. Reduced growth rates as a result of greater thermal tolerance have been described previously through both short-term acclimatory and adaptive responses. A thermally tolerant isolate of Symbiodinium A1 cultured for 10 days at $32^{\circ} \mathrm{C}$ exhibited only a slight decline in photosynthetic activity but a considerable decline in growth, compared to control temperature conditions (Robison \& Warner, 2006). In another example, evolution of thermal tolerance in the phytoplankton Chlorella vulgaris resulted in a down-regulation in respiration relative to photosynthesis through changes in energy allocation (Padfield et al., 2016).

ExROS production by the WT@31 had mean values that were always higher than those for the remaining experimental groups and up to 17 times greater by D21. Conversely, the SS@31 was able to maintain lower exROS levels similar to the WT@27 and SS@27 throughout most of the experiment. Reactive oxygen species are molecules produced as a byproduct of photosynthesis and respiration. If produced in excess and not neutralised by antioxidant molecules and enzymes, ROS are secreted extracellularly into their surrounding medium. Excessive ROS production in hospite has been linked to triggering the bleaching response of corals (Downs et al., 2002; Lesser, 2006), thus their production is an important trait to consider in Symbiodinium thermal selection experiments. Cellular ROS production can occur as a result of uncoupling of the photosystems (PSII and PSI) during heat stress (Iglesias-Prieto et al., 1992), and in excess can cause damage to DNA, proteins, lipids and 567 cell membranes (Tchernov et al., 2004; Lesser, 2006; Venn et al., 2008). The high exROS produced by the WT@31 likely explains the inability for growth and severe photo-inhibition at an elevated temperature. 
571 Two previous studies have experimented with the heterogeneous population from which our

572 WT strain was derived. Howells et al. (2011) showed that, after 11 days of heating,

573 Symbiodinium $\mathrm{C} 1$ from Magnetic Island showed no signs of stress at $32^{\circ} \mathrm{C}$ and displayed

574 maximum quantum yields $16 \%$ higher than at the control temperature of $27^{\circ} \mathrm{C}$. In a more

575 recent study, heating of the same Symbiodinium $\mathrm{C} 1$ for 15 days at $32^{\circ} \mathrm{C}$ revealed no

576 difference in photosynthetic performance, or amount of exROS compared to culture

577 replicates maintained under ambient temperature conditions. Heat-exposed cells were able to

578 acclimate via upregulation of a number of antioxidant and molecular chaperone genes (Levin

579 et al., 2016), preventing damage to the photosynthetic apparatus and allowing cell growth to

580 be maintained. In our study, D3 already represented 17 days of exposure to $31{ }^{\circ} \mathrm{C}$ for the

581 WT@31 as a result of two weeks pre-acclimation to experimental conditions. The reduced

582 performance of our WT@ 31 , and subsequent decline in fitness, indicates that more than 15

583 days are needed before thermal stress significantly impacts the WT's physiological

584 performance. The energetic costs of upregulating pathways to combat the effects of thermal

585 stress could have become too high for thermal tolerance to be maintained (DeWitt et al.,

586 1998). Maintenance of low exROS levels by the SS@ 31 could be a result of a greater

587 antioxidant capacity under heat stress (McGinty et al., 2012) compared to the WT, perhaps

588 through the selection of cells with a higher metabolic capacity able to support such costly

589 antioxidant responses. Alternatively, a more stable photosynthetic apparatus, through

590 alterations in the fatty acid composition of thylakoid membranes (Tchernov et al., 2004) for

591 example, could limit cellular ROS production in the SS cells. 
593

594

595

596

597

598

599

600

601

602

603

604

605

606

607

608

609

610

611

612

613

614

615

616

Climate change-relevant evolutionary experiments have been carried out on other microalgae, although none of these previously studied algae have a symbiotic life stage. These microalgal studies have mainly focussed on the effects of selection to an elevated $\mathrm{pCO}_{2}$ regime, and often used growth rate as the only fitness parameter measured. Some have failed to show adaptation (Crawfurd et al., 2011; Tatters et al., 2013), while others have provided evidence for adaptation to elevated $\mathrm{pCO}_{2}$ (Collins \& Bell, 2004; Lohbeck et al., 2012; Jin et al., 2013). A limited number of studies have investigated the evolutionary consequences of selection to elevated temperature; the dinoflagellate Alexandrium minutum adapted to a combination of elevated temperature and $\mathrm{pCO}_{2}$ after $\sim 250$ generations (two years) of selection (Flores-Moya et al., 2008), a number of phytoplankton strains showed interspecific differences in thermal adaptive capacity (Huertas et al., 2011) and the coccolithophore Emiliania huxleyi showed a $16 \%$ higher growth rate in thermally adapted populations after 460 generations (one year) of selection (Schlüter et al., 2014). Our results show that thermal adaptation is possible after only $\sim 80$ generations ( 2.5 years) of selection in Symbiodinium C1. Such rapid adaptation may be in part be due to the nature of our initial experimental design (ratchet technique, [Huertas et al., 2011]), where sequential increases in temperature, only to levels that maintained population growth, meant maximising the potential for beneficial, random mutations to occur and thus maximising the rate of adaptation. Additionally, a further culture of $\sim 73$ generations (more than 2 years) at elevated temperature after the ratchet experiment could have allowed any such mutations to become fixed in the population.

\section{Thermal adaptation of algal endosymbionts shows limited expression in symbiosis}

While our in vitro results provide compelling evidence for an adaptive response to temperature selection in Symbiodinium C1, the benefits of temperature adaptation showed 
limited expression in symbiosis with juvenile Acropora corals. There were no significant differences in tissue pigmentation between treatment groups and all were equally bleached at the end of the experiment when under heat stress. At the higher experimental temperature of $31^{\circ} \mathrm{C}$ there was no significant difference in growth rates between juveniles that harboured SS or WT cells but two of the three coral species harbouring the SS cells exhibited a trend of positive growth, while all species harbouring the WT displayed a trend of negative growth. Recruit growth at $27{ }^{\circ} \mathrm{C}$ was independent of infection with WT or SS cells, indicating no negative impact of thermal adaptation of the SS on holobiont growth at ambient temperature in this experiment. This contrasts with other studies that have shown that higher thermal tolerance in Symbiodinium type D comes at the cost of reduced growth for A. millepora juvenile and adult corals at ambient temperatures, as well as Pocillopora damicornis, compared to corals harbouring more thermo-sensitive C1 (Little et al., 2004), C2 (Jones \& Berkelmans, 2010) and (Cunning et al., 2015) Symbiodinium, respectively.

Differences between the in vitro and in hospite responses under heat stress have previously been reported for other Symbiodinium strains (Bhagooli \& Hidaka, 2003; Goulet et al., 2005). Our results, in conjunction with the observed differences in bleaching responses of different coral species that harbour the same Symbiodinium type (Berkelmans \& van Oppen, 2006; Abrego et al., 2008; Fisher et al., 2012), confirm that the coral host contributes considerably to the bleaching tolerance level of the coral-Symbiodinium holobiont (Baird et al., 2008). Little is known about potential host-factors influencing the holobiont response, but a number of species-specific variables have been suggested whereby the coral host can alter the algal microenvironment through differences in the amount and type of light reaching symbionts in hospite, host-based pigments (Dove, 2004; Salih et al., 2006), host skeletal morphology (Enríquez et al., 2005; Kaniewska et al., 2008) and tissue thickness (Loya et al., 2001). 
642 Further, a potentially dissolved inorganic carbon (DIC) limited environment in hospite 643 (Leggat et al., 2000; Marubini et al., 2008; Jarrold et al., 2013) could drive differences in 644 photosynthesis between in vitro cultures that may be DIC-replete. Alternatively, either the 645 production of ROS by the host itself under heat stress, or host antioxidant capacity could have 646 been so high that the increase in ROS produced by WT symbionts at $31^{\circ} \mathrm{C}$ was relatively insignificant. Furthermore, a breakdown of symbiont-host communication under stress has been suggested to affect the ability of a coral to discriminate between healthy and unhealthy Symbiodinium cells (Baird et al., 2008), which could explain factors such as host-digestion of Symbiodinium, symbiont expulsion or apoptotic host cell death (Dunn et al., 2002; Weis, 2008) as a resulting host response, regardless of Symbiodinium health ( Baird et al. 2008).

\section{Assisted Symbiodinium evolution to enhance coral bleaching tolerance}

654

655

656

657

658

659

660

661

662

663

664

665

Our results highlight the ability of Symbiodinium to evolve greater thermal tolerance over ecological time-scales relevant to the pace of climate change. A previous directed evolution experiment on Symbiodinium showed positive growth after 55-70 generations of culturing at $30^{\circ} \mathrm{C}$, while no growth was observed at this temperature prior to selection (Huertas et al., 2011). These findings indicate that the ability for the rapid temperature adaptation is not limited to the Symbiodinium C1 used in our study.

We show that the positive effect of laboratory selection on our particular Symbiodinium strain was reduced in symbiosis. Many Symbiodinium types are known to occur both free-living in coral reef sediments and the water column and in symbiosis with reef-building corals and/or other reef organisms (Littman et al., 2008; Huang et al., 2013), such as the C1 type studied here. Our findings suggest that fast growth may be an important trait to artificially select for 
when the goal is to enhance thermal tolerance in free-living Symbiodinium, but may not be an appropriate trait to select for in vitro if the aim is to augment thermal tolerance in hospite (i.e., coral bleaching tolerance) (van Oppen et al., 2015). Additional laboratory selection experiments using several selection pressures and targeted traits are required to resolve this issue. Furthermore, Symbiodinium is a highly diverse genus comprising many evolutionary lineages and types (i.e., putative species) (Baker, 2003; Manning \& Gates, 2008) and it is possible that other Symbiodinium strains belonging to different clades and types may respond to laboratory thermal selection in different ways with varying effects on the holobiont. Finally, it is important to acknowledge the numerous other microbes (e.g. bacteria, fungi, archaea) that are present in corals. These microbes can have vastly different physiologies and can play important, functional roles (Ainsworth et al., 2010). Their interaction with Symbiodinium could therefore have implications in the overall phenotype of both the Symbiodinium and the coral holobiont.

Models of reef futures under climate change have taken into account existing variation in symbiont thermal tolerance (Baskett et al., 2009) and coral resilience (Baskett et al., 2014). The results presented here on the rate of evolution in Symbiodinium to rising seawater temperatures, and the potentially different selective forces in the free-living versus the symbiotic life stage (Day et al., 2008), are critical to refine such models. Examination of cellular pathways (e.g., via transcriptome analysis) underpinning the SS and WT Symbiodinium thermal stress response in vitro and in hospite will likely provide insights into the distinct phenotypic responses observed here and may reveal why the positive effects of thermal selection were reduced in hospite in our experiment. Such studies will inform and improve experimental evolution studies in Symbiodinium for augmenting coral bleaching tolerance and their ultimate use in coral reef conservation and restoration initiatives. 


\section{Acknowledgments}

693 We thank N. E. Cantin for assistance with the camera stereo-microscope setup, D. J. Suggett 694 for advice on the interpretation of photosynthetic parameters measured, E. Puill-Stephan, E. J. Howells and R. González González for their contributions to the early stages of this work, B.L. Willis for commenting on the manuscript, B.L. Willis and B. Leggat for general advice to the experimental design and M.D. Jarrold and K.M. Quigley for advice with statistical analyses. The study was funded by the Paul G. Allen Family Foundation and the Australian Institute of Marine Science. L. J. C. acknowledges receipt of a James Cook University PostGraduate Research Scholarship (JCUPRS).

\section{References}

703

704

Abrego D, Ulstrup KE, Willis BL, van Oppen MJH (2008) Species-specific interactions between algal endosymbionts and coral hosts define their bleaching response to heat and light stress. Proceedings of the Royal Society B: Biological Sciences, 275, 2273-82.

Ainsworth TD, Thurber RV, Gates RD (2010) The future of coral reefs: a microbial perspective. Trends in Ecology \& Evolution, 25, 233-240.

Baird AH, Bhagooli R, Ralph PJ, Takahashi S (2008) Coral bleaching: the role of the host. Cell, 24, 16-20.

Baker AC (2003) Flexibility and Specificity in Coral-Algal Symbiosis: Diversity, Ecology, and Biogeography of Symbiodinium on JSTOR. Annual Review of Ecology, Evolution, and Systematics, 34, 661-689.

Baker AC, Starger CJ, McClanahan TR, Glynn PW (2004) Coral reefs: Corals' adaptive response to climate change. Nature, $\mathbf{4 3 0}, 741-741$. 
Baskett ML, Gaines SD, Nisbet RM (2009) Symbiont diversity may help coral reefs survive moderate climate change. Ecological Applications, 19, 3-17.

Baskett ML, Fabina NS, Gross K (2014) Response Diversity Can Increase Ecological Resilience to Disturbance in Coral Reefs. The American Naturalist, 184, E16-E31.

Bates D, Maechler M, Bolker B, Walker S (2015) Fitting Linear Mixed-Effects Models Using Ime4. Journal of Statistical Software, 67, 1-48.

Beardall J, Raven JA (2004) The potential effects of global climate change on microalgal photosynthesis, growth and ecology. Phycologia, 43, 26-40.

Beltran VH, Dunlap WC, Long PF (2012) Comparison of the photosynthetic bleaching response of four coral species common to the central GBR.

Berkelmans R, van Oppen MJH (2006) The role of zooxanthellae in the thermal tolerance of corals: a "nugget of hope" for coral reefs in an era of climate change. Proceedings of the Royal Society B: Biological Sciences, 273, 2305-12.

Bhagooli R, Hidaka M (2003) Comparison of stress susceptibility of in hospite and isolated zooxanthellae among five coral species. Journal of Experimental Marine Biology and Ecology, 291, 181-197.

Bythell JC (1988) A total nitrogen and carbon budget for the elkhorn coral Acropora palmata (Lamarck). Proceedings of the 6th International Coral Reef Symposium, 6, 535-540.

Cantin NE, van Oppen MJH, Willis BL, Mieog JC, Negri AP (2009) Juvenile corals can acquire more carbon from high-performance algal symbionts. Coral Reefs, 28, 405-414.

Collins S, Bell G (2004) Phenotypic consequences of 1,000 generations of selection at elevated $\mathrm{CO}_{2}$ in a green alga. Nature, 431, 566-9.

Collins S, Bell G (2006) Evolution of natural algal populations at elevated $\mathrm{CO}_{2}$. Ecology Letters, 9, 129-135.

Cooper S (1991) Bacterial growth and division: Biochemistry and regulation of prokaryotic 
Crawfurd KJ, Raven JA, Wheeler GL et al. (2011) The Response of Thalassiosira pseudonana to Long-Term Exposure to Increased $\mathrm{CO}_{2}$ and Decreased $\mathrm{pH}$ (ed Browman H). PLOS ONE, 6, e26695.

Cunning R, Gillette P, Capo T, Galvez K, Baker AC (2015) Growth tradeoffs associated with thermotolerant symbionts in the coral Pocillopora damicornis are lost in warmer oceans. Coral Reefs, 34, 155-160.

Day T, Nagel L, Van Oppen MJH, Caley MJ (2008) Factors Affecting the Evolution of Bleaching Resistance in Corals. Source: The American Naturalist, 171, 72-88.

DeWitt TJ, Sih A, Wilson DS (1998) Costs and limits of phenotypic plasticity. Trends in Ecology and Evolution, 13, 77-81.

Dove S (2004) Scleractinian corals with photoprotective host pigments are hypersensitive to thermal bleaching.

Downs C., Fauth JE, Halas JC, Dustan P, Bemiss J, Woodley CM (2002) Oxidative stress and seasonal coral bleaching. Free Radical Biology and Medicine, 33, 533-543.

Dunn SR, Bythell JC, Le Tissier MDA, Burnett WJ, Thomason JC (2002) Programmed cell death and cell necrosis activity during hyperthermic stress-induced bleaching of the symbiotic sea anemone Aiptasia sp. Journal of Experimental Marine Biology and Ecology, 272, 29-53.

Eakin C, Liu G, Gomez A et al. (2016) Global coral bleaching 2014-2017: status and an appeal for observations. Reef Encounter, 31, 20-26.

Enríquez S, Méndez ER, Iglesias-Prieto R (2005) Multiple scattering on coral skeletons enhances light absoprtion by symbiotic algae. Limnol. Oceanogr, 50, 1025-1032.

Fabina NS, Putnam HM, Franklin EC et al. (2012) Transmission Mode Predicts Specificity and Interaction Patterns in Coral-Symbiodinium Networks (ed Ferse SCA). PLoS ONE, 
766

767

768

Falkowski PG, Dubinsky Z, Muscatine L, McCloskey L (1993) Population Control in Symbiotic Corals. BioScience, 43, 606-611.

Fisher PL, Malme MK, Dove S (2012) The effect of temperature stress on coralSymbiodinium associations containing distinct symbiont types. Coral Reefs, 31, 473485.

Flores-Moya A, Costas E, López-Rodas V (2008) Roles of adaptation, chance and history in the evolution of the dinoflagellate Prorocentrum triestinum. Die Naturwissenschaften, 95, 697-703.

Flores-Moya A, Rouco M, García-Sánchez MJ, García-Balboa C, González R, Costas E, López-Rodas V (2012) Effects of adaptation, chance, and history on the evolution of the toxic dinoflagellate Alexandrium minutum under selection of increased temperature and acidification. Ecology and Evolution, 2, 1251-9.

Franklin EC, Stat M, Pochon X, Putnam HM, Gates RD (2012) GeoSymbio: a hybrid, cloudbased web application of global geospatial bioinformatics and ecoinformatics for Symbiodinium-host symbioses. Molecular Ecology Resources, 12, 369-73.

Goreau TJ, Macfarlane AH (1990) Reduced growth rate of Montastrea annularis following the 1987-1988 coral-bleaching event. Coral Reefs, 8, 211-215.

Goulet TL, Cook CB, Goulet D (2005) Effect of short-term exposure to elevated temperatures and light levels on photosynthesis of different host-symbiont combinations in the Aiptasia pallidal Symbiodinium symbiosis. Limnology and Oceanography, $\mathbf{5 0}$, $1490-1498$.

Henley WJ (1993) Measurement and interpretation of photosynthetic light-response curves in algae in the context of photoinhibition and diel changes. Journal of Phycology, 29, 729739. 
Hill R, Schreiber U, Gademann R, Larkum AWD, Kühl M, Ralph PJ (2004) Spatial heterogeneity of photosynthesis and the effect of temperature-induced bleaching conditions in three species of corals. Marine Biology, 144, 633-640.

Hoegh-Guldberg O, Mumby PJ, Hooten AJ et al. (2008) Coral Reefs Under Rapid Climate Change and Ocean Acidification. Science, 318, 1737-1742.

Hoffmann AA, Sgrò CM (2011) Climate change and evolutionary adaptation. Nature, 470, $479-85$.

Hönisch B, Ridgwell A, Schmidt DN et al. (2012) The geological record of ocean acidification. Science (New York, N.Y.), 335, 1058-63.

van Hooidonk R, Maynard J, Tamelander J et al. (2016) Local-scale projections of coral reef futures and implications of the Paris Agreement. Scientific reports, 6, 39666.

Hothorn T, Bretz F, Westfall P (2008) Simultaneous inference in general parametric models. Biometrical Journal, 50, 346-363.

Howells EJ, Beltran VH, Larsen NW, Bay LK, Willis BL, van Oppen MJH (2011) Coral thermal tolerance shaped by local adaptation of photosymbionts. Nature Climate Change, 2, 116-120.

Howells EJ, Beltran VH, Larsen NW, Bay LK, Willis BL, van Oppen MJH (2012) Coral thermal tolerance shaped by local adaptation of photosymbionts. Nature Climate Change, 2, 116-120.

Huang H, Zhou G, Yang J, Liu S, You F, Lei X (2013) Diversity of free-living and symbiotic Symbiodinium in the coral reefs of Sanya, South China Sea. Marine Biology Research, 9, 117-128.

Huertas IE, Rouco M, Lopez-Rodas V, Costas E (2011a) Warming will affect phytoplankton differently: evidence through a mechanistic approach. Proceedings of the Royal Society B: Biological Sciences, 278, 3534-3543. 
Hughes TP, Baird AH, Bellwood DR et al. (2003) Climate change, human impacts, and the resilience of coral reefs. Science (New York, N.Y.), 301, 929-33.

Hughes TP, Kerry J, Álvarez-Noriega M et al. (2017) Global warming and recurrent mass bleaching of corals. Nature, 543, 373-377.

Iglesias-Prieto R, Matta JL, Robins WA, Trench RK (1992) Photosynthetic response to elevated temperature in the symbiotic dinoflagellate Symbiodinium microadriaticum in culture. Proceedings of the National Academy of Sciences of the United States of America, 89, 10302-10305.

Iglesias-Prieto R, Beltrán VH, Lajeunesse TC, Reyes-Bonilla H, Thomé PE (2004b) Different algal symbionts explain the vertical distribution of dominant reef corals in the eastern Pacific. Proceedings of the Royal Society of London B: Biological Sciences, 271, 17571763.

Iwao K, Fujisawa T, Hatta M (2002) A cnidarian neuropeptide of the GLWamide family induces metamorphosis of reef-building corals in the genus Acropora. Coral Reefs, 21, $127-129$.

Jarrold MD, Calosi P, Verberk WCEP, Rastrick SPS, Atfield A, Spicer JI (2013) Physiological plasticity preserves the metabolic relationship of the intertidal noncalcifying anthozoan-Symbiodinium symbiosis under ocean acidification. Journal of Experimental Marine Biology and Ecology, 449, 200-206.

Jin P, Gao K, Beardall J (2013) Evolutionary responses of a coccolithophorid Gephyrocapsa oceanica to ocean acidification. Evolution, 67, 1869-78.

Jones A, Berkelmans R (2010) Potential Costs of Acclimatization to a Warmer Climate: Growth of a Reef Coral with Heat Tolerant vs. Sensitive Symbiont Types. PLoS ONE, 5, e10437.

Kaniewska P, Anthony KRN, Hoegh-Guldberg O (2008) Variation in colony geometry 
modulates internal light levels in branching corals, Acropora humilis and Stylophora pistillata. Marine Biology, 155, 649-660.

Kline DI, Teneva L, Hauri C et al. (2015) Six Month in situ high-resolution carbonate chemistry and temperature study on a coral reef flat reveals asynchronous $\mathrm{pH}$ and temperature anomalies. PLOS ONE, 10, e0127648.

Leggat W, Rees TA, Yellowlees D (2000) Meeting the photosynthetic demand for inorganic carbon in an alga-invertebrate association: preferential use of $\mathrm{CO}_{2}$ by symbionts in the giant clam Tridacna gigas. Proceedings. Biological sciences, 267, 523-9.

Lesser MP (2006a) Oxidative stress in marine environments: Biochemistry and Physiological Ecology. Annual Review of Physiology, 68, 253-278.

Lesser MP (2006b) Oxidative stress in marine environments: Biochemistry and physiological ecology. Annual Review of Physiology, 68, 253-278.

Levin RA, Beltran VH, Hill R, Kjelleberg S, McDougald D, Steinberg PD, van Oppen MJH (2016) Sex, scavengers, and chaperones: Transcriptome secrets of divergent Symbiodinium thermal tolerances. Molecular Biology and Evolution, 33, 2201-2215.

Little AF, van Oppen MJH, Willis BL (2004) Flexibility in algal endosymbioses shapes growth in reef corals. Science (New York, N.Y.), 304, 1492-4.

Littman RA, van Oppen MJH, Willis BL (2008) Methods for sampling free-living Symbiodinium (zooxanthellae) and their distribution and abundance at Lizard Island (Great Barrier Reef). Journal of Experimental Marine Biology and Ecology, 364, 48-53.

Lohbeck KT, Riebesell U, Reusch TBH (2012) Adaptive evolution of a key phytoplankton species to ocean acidification. Nature Geoscience, 5, 346-351.

Loya Y, Sakai K, Yamazato K, Nakano Y, Sambali H, van Woesik R (2001) Coral bleaching: the winners and the losers. Ecology Letters, 4, 122-131.

Manning MM, Gates RD (2008) Diversity in populations of free-living Symbiodinium from a 
Marubini F, Ferrier-Pagès C, Furla P, Allemand D (2008) Coral calcification responds to seawater acidification: a working hypothesis towards a physiological mechanism. Coral Reefs, 27, 491-499.

McGinty ES, Pieczonka J, Mydlarz LD (2012) Variations in reactive oxygen release and antioxidant activity in multiple Symbiodinium types in response to elevated temperature. Microbial Ecology, 64, 1000-1007.

Merilä J, Hendry AP (2014) Climate change, adaptation, and phenotypic plasticity: the problem and the evidence. Evolutionary Applications, 7, 1-14.

Mieog JC, Olsen JL, Berkelmans R, Bleuler-Martinez SA, Willis BL, van Oppen MJH (2009) The roles and interactions of symbiont, host and environment in defining coral fitness.

Murata N, Takahashi S, Nishiyama Y, Allakhverdiev SI (2007) Photoinhibition of photosystem II under environmental stress. Biochimica et Biophysica Acta (BBA) Bioenergetics, 1767, 414-421.

Normile D (2016) El Niño’s warmth devastating reefs worldwide. Science, 352, 15-6.

van Oppen MJH, Oliver JK, Putnam HM, Gates RD (2015) Building coral reef resilience through assisted evolution. Proceedings of the National Academy of Sciences, 112, $2307-2313$

van Oppen MJH, Gates RD, Blackall LL et al. (2017) Shifting paradigms in restoration of the world's coral reefs. Global Change Biology.

Van Oppen MJH, Souter P, Howells EJ, Heyward A, Berkelmans R (2011) Novel Genetic Diversity Through Somatic Mutations: Fuel for Adaptation of Reef Corals? Diversity, 3, $405-423$.

Padfield D, Yvon-Durocher G, Buckling A, Jennings S, Yvon-Durocher G (2016) Rapid 
evolution of metabolic traits explains thermal adaptation in phytoplankton. Ecology Letters, 19, 133-142.

Parmesan C (2006) Ecological and Evolutionary Responses to Recent Climate Change. Annual Review of Ecology, Evolution, and Systematics, 37, 637-669.

Pinheiro J, Bates D, DebRoy S, Sarkar D, R Core Team (2017) nlme: Linear and Nonlinear Mixed Effects Models. R package version 3.1-131.

Platt T, Gallegos CL, Harrison WG (1980) Photoinibition of photosynthesis in natural assemblages of marine phytoplankton. Journal of Marine Research, 38, 687-701.

R Core Team (2016). R Foundation for Statistical Computing.

Ralph PJ, Polk SM, Moore KA, Orth RJ, Smith WO (2002) Operation of the xanthophyll cycle in the seagrass Zostera marina in response to variable irradiance. Journal of Experimental Marine Biology and Ecology, 271, 189-207.

Reimer AA (1971) Observations on the relationships between several species of tropical zoanthids (Zoanthideas coelenterata) and their zooxanthellae. Journal of Experimental Marine Biology and Ecology, 7, 207-214.

Robison JD, Warner ME (2006) Differential Impacts of Photoacclimation and Thermal Stress on the Photobiology of Four Different Phylotypes of Symbiodinium (Pyrrhophyta). Journal of Phycology, 42, 568-579.

Salih A, Cox G, Szymczak R et al. (2006) The role of host-based color and fluorescent pigments in photoprotection and in reducing bleaching stress in corals. Proceedings of the 10th International Coral Reef Symposium, 746-756.

Sampayo EM, Ridgway T, Bongaerts P, Hoegh-Guldberg O (2008) Bleaching susceptibility and mortality of corals are determined by fine-scale differences in symbiont type. Proceedings of the National Academy of Sciences of the United States of America, 105, $10444-10449$. 
Schlüter L, Lohbeck KT, Gutowska MA, Gröger JP, Riebesell U, Reusch TBH (2014) Adaptation of a globally important coccolithophore to ocean warming and acidification. Nature Climate Change, 4, 1024-1030.

Schreiber U (2004) Pulse-Amplitude-Modulation (PAM) Fluorometry and Saturation Pulse Method: An Overview. In: Chlorophyll a Fluorescence, pp. 279-319. Springer Netherlands, Dordrecht.

Stat M, Morris E, Gates RD (2008) Functional diversity in coral-dinoflagellate symbiosis. Proceedings of the National Academy of Sciences of the United States of America, 105, $9256-61$.

Szmant AM, Gassman NJ (1990) The effects of prolonged "bleaching" on the tissue biomass and reproduction of the reef coral Montastrea annularis. Coral Reefs, 8, 217-224.

Takahashi S, Yoshioka-Nishimura M, Nanba D, Badger MR (2013) Thermal acclimation of the symbiotic alga Symbiodinium spp. alleviates photobleaching under heat stress. Plant physiology, 161, 477-85.

Tatters AO, Schnetzer A, Fu F, Lie AY, Caron D, Hutchins D (2013) Short- versus long-term responses to changing $\mathrm{CO}_{2}$ in a coastal dinoflagellate bloom: implications for interspecific competitive interactions and community structure. Evolution, 67, 1879-91.

Tchernov D, Gorbunov MY, de Vargas C, Narayan Yadav S, Milligan AJ, Häggblom M, Falkowski PG (2004) Membrane lipids of symbiotic algae are diagnostic of sensitivity to thermal bleaching in corals. Proceedings of the National Academy of Sciences of the United States of America, 101, 13531-5.

Thornhill DJ, Lewis AM, Wham DC, LaJeunesse TC (2014) Host-specialist lineages dominate the adaptive radiation of reef coral endosymbionts. Evolution, 68, 352-367.

Titlyanov EA, Titlyanova T V, Leletkin VA, Tsukahara J, Van Woesik R, Yamazato K (1996) Degradation of zooxanthellae and regulation of their density in hermatypic 

corals. Marine Ecology Progress Series, 139, 167-178.

941 Venn AA, Loram JE, Douglas AE (2008) Photosynthetic symbioses in animals. Journal of Experimental Botany, 59, 1069-1080.

Wang J-T, Chen Y-Y, Tew KS, Meng P-J, Chen CA (2012) Physiological and biochemical performances of menthol-induced aposymbiotic corals. PloS one, 7, e46406.

Warner ME, Fitt WK, Schmidt GW (1999) Damage to photosystem II in symbiotic dinoflagellates: A determinant of coral bleaching. Proceedings of the National Academy of Sciences of the United States of America, 96, 8007-8012.

Weis VM (2008) Cellular mechanisms of Cnidarian bleaching: stress causes the collapse of symbiosis. The Journal of Experimental Biology, 211, 3059-66.

Wilkerson FP, Kobayashi D, Muscatine L (1988) Mitotic index and size of symbiotic algae in Caribbean Reef corals. Coral Reefs, 7, 29-36.

952

Yellowlees D, Rees TA V., Leggat W (2008) Metabolic interactions between algal symbionts and invertebrate hosts. Plant, Cell \& Environment, 31, 679-694.

954

Zeebe RE, Dickens GR, Ridgwell A, Sluijs A, Thomas E (2014) Onset of carbon isotope excursion at the Paleocene-Eocene thermal maximum took millennia, not 13 years. Proceedings of the National Academy of Sciences of the United States of America, 111, E1062-3.

\section{Supporting Information}

$\mathrm{S} 1$ : Annotated ' $\mathrm{R}$ ' scripts used to analyse in vitro and in hospite data

S2: Raw data for each in vitro and in hospite traits measured 


\section{University Library}

\section{- M M N E R VA A gateway to Melbourne's research publications}

Minerva Access is the Institutional Repository of The University of Melbourne

Author/s:

Chakravarti, LJ;Beltran, VH;van Oppen, MJH

Title:

Rapid thermal adaptation in photosymbionts of reef-building corals

Date:

2017-11-01

Citation:

Chakravarti, L. J., Beltran, V. H. \& van Oppen, M. J. H. (2017). Rapid thermal adaptation in photosymbionts of reef-building corals. GLOBAL CHANGE BIOLOGY, 23 (11),

pp.4675-4688. https://doi.org/10.1111/gcb. 13702.

Persistent Link:

http://hdl.handle.net/11343/241831 